\title{
Unusual position of external carotid artery: a case report
}

\author{
S. B. Rao, V. R. Vollala, M. Rao, V. P. Samuel, Deepthinath, S. Nayak, N. Pamidi \\ Department of Anatomy, Melaka Manipal Medical College (Manipal Campus), ICHS, Manipal, Karnataka-576 104, India
}

Address for correspondence: Dr. Venkata Ramana Vollala, Lecturer, Department of Anatomy, Melaka Manipal Medical College (Manipal Campus), International Centre for Health Sciences, Manipal-576104, Karnataka State, India. E-mail: ramana_anat@yahoo.co.in

\begin{abstract}
The arterial pattern of the human body is one of the systems that show a large number of variations. Many reports are available regarding variations of common carotid, external and internal carotid arteries and branches of external carotid artery. We describe a very rare case of lateral position of external carotid artery. The external carotid artery was lateral to the internal carotid artery at the bifurcation of the common carotid artery. The clinical importance of this variation is discussed.
\end{abstract}

\section{KEY WORDS}

External carotid artery, variation, position.

\section{CASE REPORT}

uring the dissection classes in the Department of Anatomy at Mamata Medical College, a 52-yearold male cadaver showed the lateral position of external carotid artery on right side [Figure 1]. However on the left side the position of the external carotid artery was normal. We traced the artery upward for confirmation of the course and branching pattern of external carotid artery which was found to be normal.

\section{DISCUSSION}

External carotid artery (ECA) is the chief artery of head and neck region. It begins lateral to upper border of thyroid cartilage, level with disc between the third and fourth cervical vertebrae. At its origin, it is in the carotid triangle and lies anteromedial to internal carotid artery but becomes anterior and lateral to it as it ascends. It first ascends slightly forwards and then inclines backwards and a little laterally to pass midway between mastoid tip and mandibular angle where it enters substance of parotid gland and divides into terminal branches superficial temporal and maxillary arteries. In the neck the artery gives six branches, these are superior thyroid, ascending pharyngeal, lingual, facial, occipital and posterior auricular arteries. ${ }^{1}$ According to Bergman et $a l,{ }^{2}$ the ECA may be absent unilaterally or bilaterally. When unilaterally absent, the branches, usually

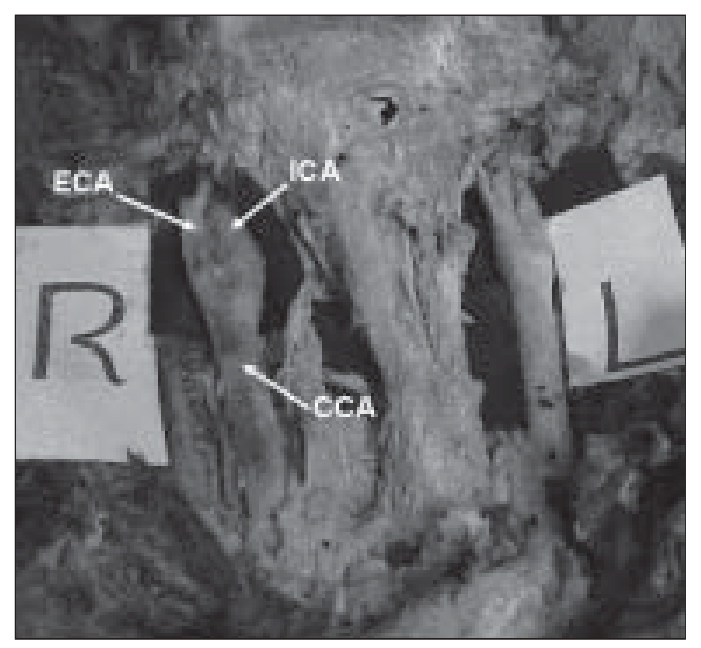

Figure 1: Lateral position of ECA on right side ECA - external carotid artery, CCA - common carotid artery, ICA - internal carotid artery

derived from it arise from the upward continuation of the common trunk or from the contralateral vessel. The artery may be located superficially, and run lateral to the Stylohyoid muscle or between the posterior belly of Digastric muscle and the Stylohyoid. In a study by Prendes et $a l,{ }^{3}$ an anatomic variant for the position of the external carotid artery (ECA) at the carotid bifurcation was noted in 5.3 percent of patients studied by Doppler ultrasound and contrast angiography. The ECA was lateral to and posterior to the internal carotid artery (ICA) in these patients. Consideration of this important variation is mandatory for accurate ultrasound image correlation. 
There are reports of lateral position of ECA.,5,6 According to Bussaka et al, lateral position of the external carotid artery was seen in 17 cases $(4.3 \%)$, of which 13 cases were on the right side and 4 cases on the left. It is necessary to know the lateral position of the external carotid artery for the correct diagnosis by intravenous digital subtraction angiography (IVDSA) and doppler scanning. During bleeding from terminal branches of ECA occasionally it is necessary to consider ligation of the artery. It is very important to ensure that the artery being ligated is indeed the ECA rather than internal carotid as ligation of latter causes a high risk of hemi paresis. An unusual case of peripheral hypoglossal nerve palsy, caused by lateral position of the external carotid artery and an abnormally high carotid bifurcation has been reported ${ }^{7}$. Improvement followed ligation and cutting of the external carotid artery at its origin. The present variation may be of particular interest to surgeons and anatomists.

\section{REFERENCES}

1. Williams PL, Bannister LH, Berry MM, Collins P, Dyson M, Ferguson MWJ. Grays Anatomy, $38^{\text {th }}$ edn. Churchill \& Livingstone, Baltimore, 1515, 1995.

2. Bergman RA, Thompson SA, Afifi AK, Saadeh FA. Compendium of human anatomic variations. Urban \& Schwarzenberg. BaltimoreMunich 65, 1988.

3. Prendes JL, McKinney WM, Buonanno FS, Jones AM. Anatomic variations of the carotid bifurcation affecting Doppler scan interpretation. J clin Ultrasound 1980;8:147-50.

4. Bussaka H, Sato N, Oguni T, Korogi M, Yamashita Y, Takahashi M. Lateral position of ECA. Rhinsho hoshasen 1990;35:1061-3.

5. Handa J, Matsuda M, Handa $\mathrm{H}$. Lateral position of the external carotid artery. Report of a case. Radiology 1972;102:361-2.

6. Braeuer NR, Mallamo JT, Lynch RD. Anomalous lateral and inferior position of the external carotid artery: case report. J Can Assoc Radiol 1975;26:210-11.

7. Ueda S, Kohyama Y, Takase K. Peripheral hypoglossal nerve palsy caused by lateral position of the external carotid artery and an abnormally high position of bifurcation of the external and internal carotid arteries_a case report. Stroke 1984;15:736-9. 